NOTE

\title{
On the attraction of larval fishes to reef sounds
}

\author{
David A. Mann ${ }^{1, *}$, Brandon M. Casper ${ }^{1}$, Kelly S. Boyle ${ }^{2}$, Timothy C. Tricas ${ }^{2}$ \\ ${ }^{1}$ College of Marine Science, University of South Florida, 140 Seventh Avenue South, St. Petersburg, Florida 33701-5016, USA \\ ${ }^{2}$ Department of Zoology and Hawai'i Institute of Marine Biology, University of Hawai'i at Manoa, 2538 The Mall, Honolulu, \\ Hawaii 96822, USA
}

\begin{abstract}
Several recent studies have shown that some larval fishes will approach underwater speakers that broadcast reef noise, leading to the hypothesis that larval fishes use acoustic cues to locate reefs for settlement. The purpose of the present study was to examine existing hearing data of fishes in relation to ambient sound levels around reefs to estimate the distance over which reef fish might detect reefs sounds, and to highlight how future data should be collected to answer this important question. The few available measurements of larval fish hearing indicate that they have poor acoustic sensitivity relative to sound levels found around reefs. The apparent poor sensitivity of larval fishes to sound pressure suggests that particle motion, the back and forth motion of water that is associated with acoustic pressure, is the principal stimulus for larval fish hearing. To estimate the maximum distance of orientation to reefs, the acoustic particle velocity of reef sound was calculated from measurements of the acoustic pressure on and away from shore, assuming conditions of a planar propagating wave. Based on these calculations, we propose that larval fishes in acoustically unbounded habitats most probably cannot detect the ambient noise of particle motion at distances $>1 \mathrm{~km}$. To better understand the distances over which larval fishes can detect sounds from reefs, more studies on larval fish hearing and reef noise are needed. Larval fish hearing measurements need to independently distinguish sensitivities to particle motion and acoustic pressure. Likewise, independent measurements of particle motion around reefs are required.
\end{abstract}

KEY WORDS: Larval fish $\cdot$ Hearing $\cdot$ Ambient noise $\cdot$ Underwater acoustics $\cdot$ Sound

Resale or republication not permitted without written consent of the publisher

\section{LARVAL REEF FISH RECRUITMENT AND ACOUSTIC CUES}

The successful recruitment of fish larvae has profound implications on the structure of reef communities. The early life history of most coral reef fishes is characterized by either broadcast or benthic spawning followed by a pelagic larval phase. Fish larvae must then return to nearshore waters, metamorphose and settle as juveniles on the reef. Retention of reef fish larvae may also be a dominant feature of reef fish population dynamics (Cowen et al. 2006). Much work on the recruitment of larval fishes to the reef has focused on stochastic processes that include temporally variable reproductive patterns and physical factors involved in larval transport and settlement (Sale 1991, 2002). However, recent work indicates that pre-settlement larvae are robust swimmers (Stobutzki \& Bellwood 1997, Leis et al. 2002) and may use sensory cues to locate reefs for recruitment (Atema et al. 2002, Myrberg \& Fuiman 2002).

Several recent studies have shown that some larval fishes will approach underwater speakers broadcasting reef noise (Tolimeiri et al. 2000, 2004, Leis et al. 2003, Simpson et al. 2004, 2005a). This has led to the hypothesis that larval fishes are able to 'listen' for sounds indicating the location of coral reefs and then actively swim towards them for settlement (Tolimeiri et al. 2000, 2004, Higgs 2005, Simpson et al. 2005a). Such behavioral field experiments are very difficult to conduct, and they show that larval fish can detect and ori- 
ent to sound fields. We propose that these experiments have demonstrated attraction, but have not yet shown that larval fish can detect reefs using natural sound from great distances. For instance, about $1 \mathrm{~km}$ from the coast, Tolimieri et al. (2004) used sound levels $20 \mathrm{~dB}$ above ambient levels and pointed out a paradox between the apparent successful field attraction experiments and hearing measurements conducted in the laboratory. Here, based upon the current data on reef sound levels and fish hearing sensitivity, we provide estimates of the distance at which larval fish might detect reef sounds. The main purpose is to encourage more research on the physical and spatial characteristics of natural reef sounds to which fish may recruit, and promote research to better understand the hearing capabilities of larval fishes.

\section{ADEQUATE ACOUSTIC STIMULUS: PARTICLE VELOCITY OR SOUND PRESSURE?}

The primary stimulus in fish hearing is the particle motion component of sound that induces whole body movements of the fish relative to the otoliths of its inner ear (Schellart \& Popper 1992). In addition to direct detection of the particle motion of a sound field, some fishes with swimbladders may indirectly detect the pressure signal via re-radiated particle motion from a swimbladder (Popper \& Fay 1999). The sensitivity to acoustic pressure is a function of the swimbladder's proximity to the ear, and whether there is any physical coupling between it and the inner ear, as in otophysans such as zebrafish (Higgs et al. 2003). Adults of at least 21 families have extensions or direct mechanical connections between the swimbladder and inner ear (Webb et al. 2006) including common reef species (e.g. species of Chaetodon and Myripristis). Measurements of pressure sensitivity in embryonic, larval, and newly settled damselfishes suggest a low sensitivity to acoustic pressure (Egner \& Mann 2005, Simpson et al. 2005b, Wright et al. 2005).

Sound fields produced by underwater speakers (such as used in recent experiments) are not equivalent to sound fields in the open ocean at large distances from the sound source (e.g. Kalmijn 1988). At large distances from the sound source, the sound field approaches a plane wave where there is a simple relationship between pressure and particle velocity:

$$
p=\rho c V
$$

where $p=$ pressure $\left(\mathrm{Pa}, \mathrm{kg} \mathrm{m}^{-1} \mathrm{~s}^{-2}\right), \rho=$ water density $\left(\mathrm{kg} \mathrm{m}^{-3}\right), c=$ speed of sound $\left(\mathrm{m} \mathrm{s}^{-1}\right)$ and $V=$ particle velocity $\left(\mathrm{m} \mathrm{s}^{-1}\right)$.

Thus, a measurement of the pressure at a large distance from the source allows estimation of the particle velocity. It is important to note that otolith organs respond to particle acceleration (Kalmijn 1988), which is directly proportional to particle velocity:

$$
a=v \times 2 \pi f
$$

where $a=$ particle acceleration $\left(\mathrm{m} \mathrm{s}^{-2}\right)$ and $f=$ frequency $(\mathrm{Hz})$. Our analysis will be presented in terms of particle velocity for simplicity.

In many of the above attraction and hearing experiments, the fish could be in the near field of the sound source, where the particle velocities are typically much higher for a given sound pressure than is found in the far field. The particle velocities were neither measured nor estimated in these experiments. For a monopole sound source generating sinusoidal waves, the far field can be approximated as the distance greater than 1 wavelength (Kalmijn 1988, Rogers \& Cox 1988). Given the inverse relationship between frequency and wavelength, the size of the near field will be larger for lower frequency sounds. For example, at $100 \mathrm{~Hz}$, the wavelength of the sound is approximately $15 \mathrm{~m}$ :

$$
\lambda=c / f
$$

where $\lambda=$ wavelength $(\mathrm{m}), \quad C=$ speed of sound $\left(\sim 1500 \mathrm{~m} \mathrm{~s}^{-1}\right.$ for saltwater $)$ and $f=$ frequency $(\mathrm{Hz})$.

Thus, in relation to low-frequency monopole reef sounds, pelagic fish larvae at great distances from the inshore reef sound source are in the far field, not the near field. It is important to note that the sounds coming from a reef are not simply monopole, but are generated by numerous organisms and physical processes along the reef, creating a complex signal. Thus, actual measurements of the acoustic field including both pressure and particle velocity are necessary to understand fully what acoustic signals are available to larval fishes.

To determine the direction of the acoustic source, a fish would have to either sense particle motion (which is a vector quantity) or sample acoustic pressure over space. Because current estimates indicate that larval and post-larval fishes have low sensitivity to acoustic pressure, the maximum distance that a fish could detect typical reef noise by use of acoustic particle velocity information is estimated below.

Threshold for detection of particle velocity of adult Pacific fat sleepers (Eleotridae) is $7.5 \times 10^{-7} \mathrm{~m} \mathrm{~s}^{-1}$ (displacement $=1.2 \mathrm{~nm} \mathrm{RMS}$ ) at $100 \mathrm{~Hz}$, which is typically a highly sensitive frequency (Lu et al. 1998). While the brackish-water sleepers are not residents of coral reefs, they have marine planktonic larvae that must recruit to shore and for which there exists a good estimate of particle velocity sensitivity for adults. With regard to the hearing abilities of post-settlement sergeant majors, all fish tested had evoked potential hearing thresholds above $100 \mathrm{~dB}$ re $1 \mu \mathrm{Pa}$ at $100 \mathrm{~Hz}$ 
(Egner \& Mann 2005). The particle velocity of a $100 \mathrm{~Hz}$ sound at $100 \mathrm{~dB}$ re $1 \mu \mathrm{Pa}$ was measured with a calibrated neutrally buoyant geophone (Acoustech) in this test chamber and found to be $3.5 \times 10^{-5} \mathrm{~m} \mathrm{~s}^{-1}$ (displacement $=55 \mathrm{~nm}$ RMS). Because hearing tests are made in enclosed tanks, the particle velocities are usually higher than in open water for the same sound pressure. It is also important to note that evoked potential measurements typically underestimate hearing sensitivity (Kenyon et al. 1998, Mann et al. 2001).

We first estimate the particle velocity associated with a sound field measured $4.3 \mathrm{~km}$ from Feather Reef, northern Australia (McCauley 1997). The spectrum level sound was approximately $80 \mathrm{~dB}$ re $1 \mu \mathrm{Pa}$ $\mathrm{Hz}^{-1 / 2}$. This corresponds to an RMS level from 100 to $200 \mathrm{~Hz}$ of $90 \mathrm{~dB}$ re $1 \mu \mathrm{Pa}(\mathrm{RMS}=$ spectrum level + $10 \log$ [bandwidth, Hz]). This sound field was measured from a reef where there were high levels of reef fish chorusing and represents a relatively high combined sound source level. Using Eq. (1) the particle velocity of a $90 \mathrm{~dB}$ re $1 \mu \mathrm{Pa}$ signal would be $2.06 \times$ $10^{-8} \mathrm{~m} \mathrm{~s}^{-1}$. The threshold for detection for the sleeper at $100 \mathrm{~Hz}$ is $7.5 \times 10^{-7} \mathrm{~m} \mathrm{~s}^{-1}$ and for the post-settlement sergeant major $3.5 \times 10^{-5} \mathrm{~m} \mathrm{~s}^{-1}$. Thus at a range of $4.3 \mathrm{~km}$, the particle velocity of this signal would not likely be detectable by these fish.

For the sergeant major the hearing sensitivity in this frequency range is approximately 3 orders of magnitude higher than the predicted particle velocity. It is important to note that if the evoked potential hearing measurements were $20 \mathrm{~dB}$ higher than behavioral sensitivity (i.e. $3.5 \times 10^{-6} \mathrm{~m} \mathrm{~s}^{-1}$ ), their hearing threshold would be 2 orders of magnitude higher than the acoustic particle velocity. Therefore, the sergeant major should still not be able to detect this sound at $4.3 \mathrm{~km}$.

Based on these values, one could also estimate the sound source level required for detection at a given distance from the reef. The pressure of a far-field signal necessary to generate a particle velocity of $7.5 \times$ $10^{-7} \mathrm{~m} \mathrm{~s}^{-1}$ is $121 \mathrm{~dB}$ re $1 \mu \mathrm{Pa}$. Assuming spherical spreading loss $(\mathrm{TL}=20 \log \mathrm{R}$, where $\mathrm{TL}=$ transmission loss and $\mathrm{R}=$ distance in meters from the source), even with a loud sound level of $160 \mathrm{~dB}$ re $1 \mu \mathrm{Pa}$, similar to the source level of fish choruses recorded in the Great Barrier Reef (McCauley \& Cato 2000), the sound would only be detectable at $89 \mathrm{~m}$ from the reef (Fig. 1). With cylindrical spreading loss ( $\mathrm{TL}=10 \log \mathrm{R})$, in which sound is bounded ideally by parallel planes of the sea surface and bottom, the distance of detection could be much farther (up to $7.9 \mathrm{~km}$ ). However, reef sounds are most likely to propagate at some intermediate function of spherical and cylindrical spreading that results in complex spatial distributions of potential acoustic cues. This highlights the need for actual measurements of sound fields at different distances from the reef.

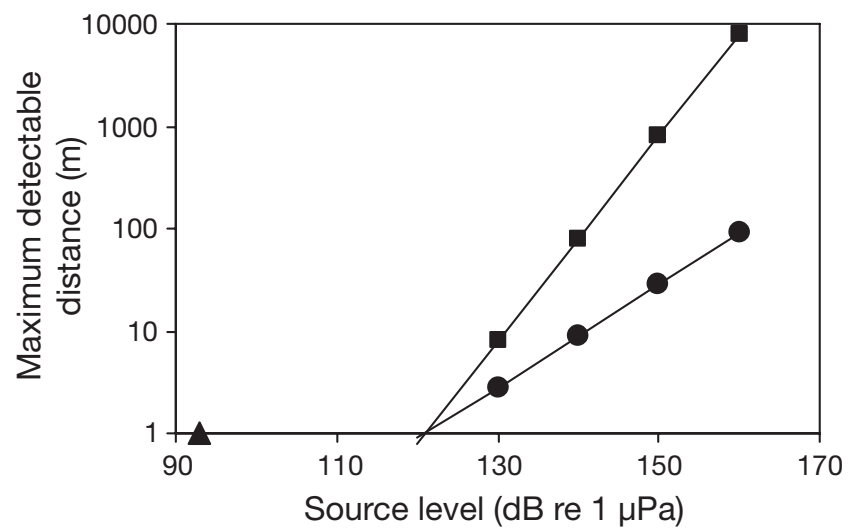

Fig. 1. Estimated maximum distance of detection for a larval fish (based on sleeper goby thresholds) that detects acoustic particle velocity, assuming spherical (@) (i.e. -20 log [distance]) or cylindrical (ם) spreading loss (i.e. -10 log [distance]). Sound level represents source level of acoustic pressure at the reef. $\boldsymbol{\Delta}$ : typical ambient noise near Hawaii (T. C. Tricas \& K. S. Boyle unpubl. data) and Lizard Island (Simpson et al. 2005a, their supplementary material)

Indeed, most of the time the ambient sound level near Lizard Island is approximately $92 \mathrm{~dB}$ re $1 \mu \mathrm{Pa}$ (Simpson et al. 2005a, their supplementary material). Sound levels on Hawaiian reefs in north Kona during daylight hours of the summer, which is the recruitment period for many Hawaiian reef species (Walsh 1987), have an RMS level from 0 to $24 \mathrm{kHz}$ of $93 \mathrm{~dB}$ re $1 \mu \mathrm{Pa}$ (T. C. Tricas \& K. S. Boyle unpubl. data). Based on the sensitivity and the physics of acoustic field detection and the assumption of spherical or cylindrical spreading, we estimate that larval fishes under these conditions cannot detect the sounds from a reef from any great distance beyond $1 \mathrm{~km}$.

\section{FUTURE DIRECTIONS}

The reef attraction studies have clearly shown that larval fishes are capable of orienting to relatively loud sounds, which in itself is an important finding. Minimally, sounds play a role in microhabitat selection and settlement (Simpson et al. 2005a). What needs to be examined is the ability of larval fish to orient over longer distances. One of the difficulties in these experiments is that the reef is always present and generating its own sound field, hence the need to use artificially high sound levels. Thus, it is impossible to separate the reef sound field from the sound field generated by the speaker. Perhaps adequate experiments could be conducted on larval fishes transported to open blue water and stimulated with synthesized reef noise from a large sound projector kilometers away to avoid such confounding cues. 
Although particle motion stimulates the otolith organs of fishes, we do not know whether larval fishes can also detect sound pressure via their swimbladders. Our rough calculations suggest that if they only detect and use particle motion as an orientation cue, then they are probably incapable of orienting to the reefs at large $(>1 \mathrm{~km})$ distances. One of the shortcomings of the hearing measurements, our own included, is that thresholds are presented in units of sound pressure, without measurement of the particle motion components (Egner \& Mann 2005, Simpson et al. 2005b, Wright et al. 2005). It is likely that the particle velocities in the laboratory setups are much greater than those found in a direct field for the same sound pressure.

The present study reveals the need for more critical work on the hearing capabilities of fish larvae and also the acoustic regimes that may attract them to reefs. Future experiments need to independently test larval fish threshold sensitivities to particle motion and sound pressure. These hearing data can then be coupled with sound pressure and particle motion measurements of sound fields around reefs to understand the distances over which larval fishes detect and orient to them.

Acknowledgements. We thank D. Higgs, A. Mooney and M. Lammers for valuable comments and discussions on a draft of this manuscript. This paper is derived from a lively meeting among members of the Mann and Tricas laboratories at USF, St. Petersburg, Florida, on July 11, 2005.

\section{LITERATURE CITED}

Atema JK, Kingsford MJ, Gerlach GG (2002) Larval reef fish could use odour for detection, retention and orientation to reefs. Mar Ecol Prog Ser 241:151-160

Cowen RK, Paris CB, Srinivasan A (2006) Scaling of connectivity in marine populations. Science 311:522-527

Egner SA, Mann DA (2005) Auditory sensitivity of sergeant major damselfish Abudefduf saxatilis from post-settlement juvenile to adult. Mar Ecol Prog Ser 285:213-222

Higgs DM (2005) Auditory cues as ecological signals for marine fishes. Mar Ecol Prog Ser 287:278-281

Higgs DM, Rollo AK, Souza MJ, Popper AN (2003) Development of form and function in peripheral auditory structures of the zebrafish (Danio rerio). J Acoust Soc Am 113: $1145-1154$

Kalmijn AJ (1988) Hydrodynamic and acoustic field detection. In: Atema J, Fay RR, Popper AN, Tavolga WN (eds) Sensory biology of aquatic animals. Springer-Verlag, New York, p 83-130

Kenyon TN, Ladich F, Yan HY (1998) A comparative study of hearing ability in fishes: the auditory brainstem response approach. J Comp Physiol A 182:307-318

Leis JM, Carson-Ewart BM, Cato DH (2002) Sound detection in situ by the larvae of a coral-reef damselfish (Pomacen-

Editorial responsibility: Jon Hare (Contributing Editor), Narragansett, Rhode Island, USA tridae). Mar Ecol Prog Ser 232:259-268

Leis JM, Carson-Ewart BM, Hay AC, Cato DH (2003) Coralreef sounds enable nocturnal navigation by some reef-fish larvae in some places and at some times. J Fish Biol 63: $724-737$

Lu Z, Song J, Popper AN (1998) Encoding of acoustic directional information by saccular afferents of the sleeper goby, Dormitator latifrons. J Comp Physiol 182:805-815

Mann DA, Higgs DM, Tavolga WN, Souza MJ, Popper AN (2001) Ultrasound detection by clupeiform fishes. J Acoust Soc Am 109:3048-3054

McCauley RD (1997) Aspects of marine biological sound in northern Australia IV: reef associated fish choruses. Defence Science and Technology Organization, Canberra

McCauley RD, Cato DH (2000) Patterns of fish calling in a nearshore environment in the Great Barrier Reef. Phil Trans R Soc Lond B 355:1289-1293

Myrberg AA Jr, Fuiman LA (2002) In: Sale PF (ed) The sensory world of reef fishes. Coral reef fishes. Academic Press, New York, p 123-148

Popper AN, Fay RR (1999) The auditory periphery in fishes. In: Fay RR, Popper AN (eds) Comparative hearing: fish and amphibians. Springer-Verlag, New York, p 43-100

Rogers PH, Cox M (1988) Underwater sound as a biological stimulus. In: Atema J, Fay RR, Popper AN, Tavolga WN (eds) Sensory biology of aquatic animals. Springer-Verlag, New York, p 131-149

Sale PF (1991) Reef fish communities: open nonequilibrial systems. In: Sale PF (ed) The ecology of fishes on coral reefs. Academic Press, San Diego, CA, p 564-600

Sale PF (2002) Coral reef fishes. Academic Press, New York

Schellart NAM, Popper AN (1992) Functional aspects of the evolution of the auditory system of actinopterygian fish. In: Webster DB, Fay RR, Popper AN (eds) The evolutionary biology of hearing. Springer-Verlag, New York, p 295-322

Simpson SD, Meekan MG, McCauley RD, Jeffs A (2004) Attraction of settlement-stage coral reef fishes to reef noise. Mar Ecol Prog Ser 276:263-268

Simpson SD, Meekan M, Montgomery J, McCauley R, Jeffs A (2005a) Homeward sound. Science 308:221

Simpson SD, Yan HY, Wittenrich ML, Meekan MG (2005b) Response of embryonic coral reef fishes (Pomacentridae: Amphiprion spp.) to noise. Mar Ecol Prog Ser 287:201-208

Stobutzki IC, Bellwood DR (1997) Sustained swimming abilities of the late pelagic stages of coral reef fishes. Mar Ecol Prog Ser 149:35-41

Tolimieri N, Jeffs A, Montgomery JC (2000) Ambient sound as a cue for navigation by the pelagic larvae of reef fishes. Mar Ecol Prog Ser 207:219-224

Tolimieri N, Haine O, Jeffs A, McCauley RD, Montgomery JC (2004) Directional orientation of pomacentrid larvae to ambient reef sound. Coral Reefs 23:184-191

Walsh WJ (1987) Patterns of recruitment and spawning in Hawaiian reef fishes. Environ Biol Fish 18:257-276

Webb JF, Smith WL, Ketten DR (2006) The laterophysic connection and swim bladder of butterflyfishes in the genus Chaetodon (Perciformes: Chaetodontidae). J Morphol 267:1338-1355

Wright KJ, Higgs DM, Belanger AJ, Leis JM (2005) Auditory and olfactory abilities of pre-settlement larvae and postsettlement juveniles of a coral reef damselfish (Pisces: Pomacentridae). Mar Biol 147:1425-1434

Submitted: February 3, 2006; Accepted: August 7, 2006

Proofs received from author(s): April 20, 2007 